\title{
Effects of yellow natural dyes on handmade Daqian paper
}

\author{
Yanbing Luo ${ }^{1 *}$ (D) and Xiujuan Zhang ${ }^{2}$
}

\begin{abstract}
Natural yellow plant dyes and traditional medicines were used widely on historical papers in ancient China for religious reasons and conservation considerations. This study aims to evaluate some traditional yellow botanical sources of dyes that contain different chemical colorant compositions in order to understand their effects on the properties of traditional handmade paper. The physical and chemical changes in paper specimens treated with plant dyes were studied by examining properties such as the color, $\mathrm{pH}$, thermogravimetric (TG) characteristics, tensile strength, folding endurance and microstructure by scanning electron microscopy (SEM). The results indicated that different colorants had different toning effects and that the main components, including carboxyl and ketone groups, could affect the paper stability at high temperatures. The results also revealed that the mechanical properties of paper specimens were improved after treatment with plant dyes. The significant improvements in the tensile strength and folding endurance and the slightly higher decomposition temperature of Amur cork tree-dyed paper could be ascribed to the strong interaction between the colorants' main components and the fibers. The scientific evaluation of the property changes is therefore valuable information for weighing the advantages and disadvantages of the various yellow toning materials for paper conservation treatment.
\end{abstract}

Keywords: Yellow natural dyes, Property changes, Historical paper, Conservation

\section{Introduction}

Throughout history, botanically-sourced dyes extracted from locally available plants have been used to color papers, textiles and other objects. According to the remaining colored ancient Chinese books, yellow dyes have been widely used for thousands of years. The most famous of these books are the large collections of ancient Buddhist manuscripts at Dunhuang, some of which were dyed yellow $[1,2]$. There are many reasons for the use of plants rich in yellow colorants in China: religious purposes (yellow represents solemnity in Buddhism); in hierarchical symbols because yellow was regarded as an imperial color-the emperors and imperial family of China were the only ones allowed to wear yellow robes;

\footnotetext{
*Correspondence: luoybs@126.com

${ }^{1}$ School of History and Culture, National Center for Experimental Archaeology Education, Sichuan University, Chengdu 610064, China Full list of author information is available at the end of the article
}

the high tinctorial strength of these plant dyes; the vividness of the colors obtained from them (even though some are not very colorfast); their ease of use; and last, conservation considerations, since yellow alkaloid dyes have insecticidal properties; that is, berberine, curcumin, crocetin and rutin dyes can be used as antioxidants and antibacterial materials. Even the Chinese government decree of AD 675 stated that yellow paper should be used by various government offices when issuing decrees and orders since white paper was often damaged by insects [3].

The yellow or golden color of autumn leaves, roots and tree bark are important sources of yellow dyes and paints. Since the earliest times, dyers worldwide have discovered a wealth of yellow dyes in many botanical sources. The pagoda bud (called huaimi in Chinese, the pagoda flower and bud of Sophora japonica L.), gardenia (called zhizi in Chinese, the fruit of Gardenia jasminoides Ellis), turmeric (called qianhuang in Chinese,

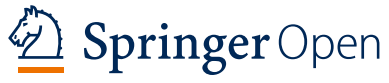

(c) The Author(s) 2021. Open Access This article is licensed under a Creative Commons Attribution 4.0 International License, which permits use, sharing, adaptation, distribution and reproduction in any medium or format, as long as you give appropriate credit to the original author(s) and the source, provide a link to the Creative Commons licence, and indicate if changes were made. The images or other third party material in this article are included in the article's Creative Commons licence, unless indicated otherwise in a credit line to the material. If material is not included in the article's Creative Commons licence and your intended use is not permitted by statutory regulation or exceeds the permitted use, you will need to obtain permission directly from the copyright holder. To view a copy of this licence, visit http://creativecommons.org/licenses/by/4.0/. The Creative Commons Public Domain Dedication waiver (http://creativeco mmons.org/publicdomain/zero/1.0/) applies to the data made available in this article, unless otherwise stated in a credit line to the data. 
the rhizome of Curcuma longa L.), and the Amur cork tree (called huangbo in Chinese, the inner part of the bark of Phellodendron amurense Rupr.), were known and used for thousands of years in China. The dyes can be fixed onto paper fibers by a brushing or pulling process without the need for a mordant, a quality that makes them quite easy to use and that, along with their fair anti-insect and/or colorfastness properties, has ensured their long-lasting popularity with dyers. A description of how to use the pagoda bud for dyeing was included in the eighth century Bencao shiyi [4]. The cultivation and use of gardenia for dyeing have been recorded since the Northern and Southern Dynasties (420-589 AD) [5]. Turmeric was recorded as a yellow dye in historical documents such as Bencao gangmu (本草纲目, Compendium of Materia Meica, 1578)[6]. A detailed description of the preparation of Amur cork tree dye for dyeing paper was found in Qiming yaoshu (齐民要术, Main techniques for the welfare of the people, ca. 533-544 AD), written during the Northern Dynasty (386-534 AD)[7]. Multidisciplinary research involving botanists, historians and chemists has already yielded interesting results, showing that these yellow dye plants contain different color sources [8]. Gardenia contains crocin and crocetin colorants and produces colors ranging from yellow to orange-red. Turmeric contains curcumin and provides a bright yellow color. Amur cork tree contains the colorant berberine, a kind of bright yellow material. The main colorant in the pagoda buds from opened/unopened pagoda trees has been identified as rutin. In China, all of these dyes could be used directly without mordant dyeing papers. Usually, dried botanical sources are thoroughly soaked, pounded, boiled and pressed in a cloth sack. The prepared liquid is saved and heated to a certain temperature to dye paper by a brushing or pulling process.

As an increasing number of historical papers have been discovered that have been dyed with different botanical yellow dyes, learning how these plant dyes affect the properties of traditional handmade papers is of interest. Paper conservators and museum professionals will be able to make better decisions when selecting colorants for conservation treatment. There have been some reports about natural yellow dyes used in ancient objects [9-13]; unfortunately, very few reports on ancient paper properties have been published prior to now. Considering the many works on natural yellow dyes, a strong project might result in several papers. In the present study, we limited our research to comparing the properties of handmade paper dyed with four different natural yellow dyes. To avoid contamination by other materials, no mordant was used during the dyeing process.

\section{Experimental}

\section{Materials}

Handmade Daqian paper (25.46 $\mathrm{g} / \mathrm{m}^{2}$ in grammage and $94 \mu \mathrm{m}$ in thickness), in which the paper pulp was not bleached, was obtained from the Daqian Paper Shop in Sichuan Province.

The gardenia, pagoda bud, turmeric, and Amur cork tree materials were purchased from a local Chinese medicine store in Chengdu. All materials were purchased commercially and used as received. Photographic images of these botanical sources are presented in Fig. 1.

\section{Preparation of colorant dyes}

The dyeing process for botanical sources usually includes sourcing botanical plants, extracting dyeing components and dyeing while controlling parameters such as temperature and time duration in dyeing experiments. In our experiments, the dyestuff extraction procedure was based on traditional Chinese recipes adopted for laboratory procedures, and a liquor ratio of $1 \mathrm{~g}$ of plant material to $20 \mathrm{~mL}$ deionized water was maintained [14-16]. Commercially available plant materials (50 g) were chopped into small pieces and soaked at room temperature in $500 \mathrm{~mL}$ of deionized water for a period of $12 \mathrm{~h}$, followed by gradually heating the mixtures to boiling and simmering them at $80{ }^{\circ} \mathrm{C}$ with regular stirring for $30 \mathrm{~min}$. Then, the liquor was obtained by sedimentation and mixed with pure juice pressed from the boiled dregs in a piece of cloth sack. This procedure was repeated twice to allow as many of the colorants as possible to come out of the plants. Both times, as much liquid as possible was mixed and saved for later use. Photographic images of the prepared colorant dyes are presented in Fig. 2.

\section{Preparation of the dyed paper samples}

The dyed paper samples were prepared by pulling papers in different temperature colorant dyes according to traditional Chinese recipes and the stability and solubility of different colored compound: the colorant dyes were kept at $40-50{ }^{\circ} \mathrm{C}$ when dyeing with the gardenia and pagoda bud dyes, at $50-60{ }^{\circ} \mathrm{C}$ with the turmeric dye, and at $80-90{ }^{\circ} \mathrm{C}$ with the Amur cork tree dye. The treated papers were hung on glass rods at $20-25{ }^{\circ} \mathrm{C}$ for $48 \mathrm{~h}$. These dyed paper samples were labeled YP-A, YP-P, YP-G, or YP-T, where $A, P, G$, and $T$ indicated the plant dyes of the Amur cork tree (A), pagoda bud (P), gardenia (G) and turmeric $(\mathrm{T})$. The untreated paper samples were labeled YP-0. Photographic images of the colorant dyed papers are presented in Fig. 3. 

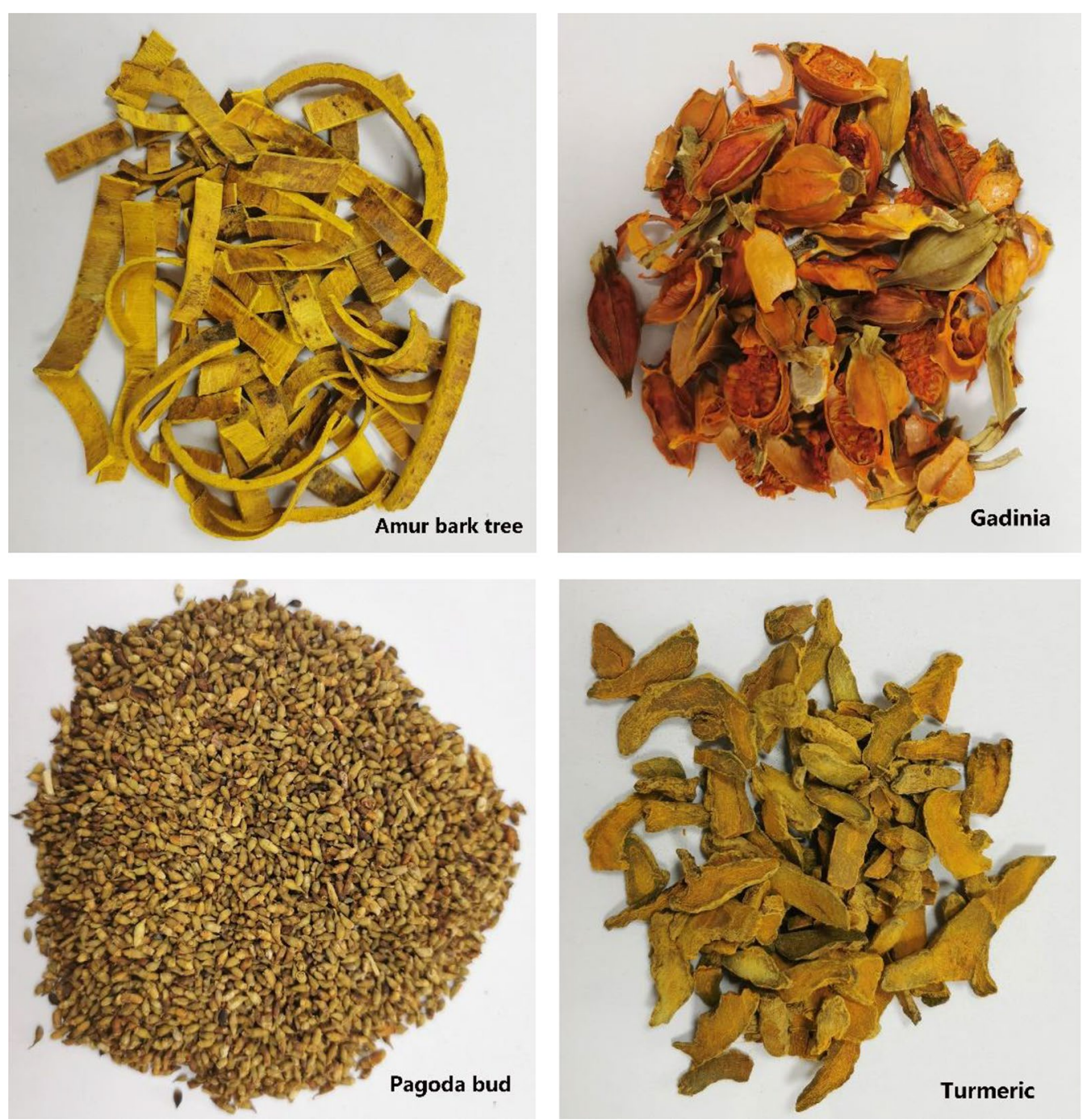

Fig. 1 Photographic images of botanical sources of yellow natural dyes

\section{Characterization}

\section{$\mathrm{pH}$ tests of colorant dyes}

Portable $\mathrm{pH}$ measurements (Horiba, LAQUA twin$\mathrm{pH}-22$ ) were used to test the $\mathrm{pH}$ of the prepared colorant dyes. The light shield cover was opened, and 3-4 drops of liquid colorant dyes were placed on the flat sensor to cover the entire flat sensor. The dye was allowed to rest on the sensor until the measured value was displayed.

\section{pH tests of papers}

The $\mathrm{pH}$ tests of the papers were carried out under laboratory conditions using a cold extraction measurement, which is more accurate than a surface method but also more destructive. For this method, $1 \mathrm{~g}$ of paper samples was cut into small fractions and left in $100 \mathrm{ml}$ of cold, distilled water for $1 \mathrm{~h}$. Then, the $\mathrm{pH}$ of the cold extract was analyzed without filtration under stirring using a Mettler Toledo Inlab Power pH meter (Mettler Toledo, Switzerland) according to the standard ISO 65881:2012 [17]. The accuracy of the $\mathrm{pH}$ measurements was an average $\mathrm{pH}< \pm 0.02$ units $(\mathrm{n}=5)$.

\section{Weight change measurements of paper}

The percentage of weight change of the paper was calculated from the following equations. All the values presented are the average of three specimens.

$$
\text { Weight change }(\%)=100 \times \frac{\mathrm{W}_{d}-W_{0}}{W_{0}}
$$

where $W_{d}$ is the weight of dyed paper and $W_{0}$ is the weight of undyed paper. 


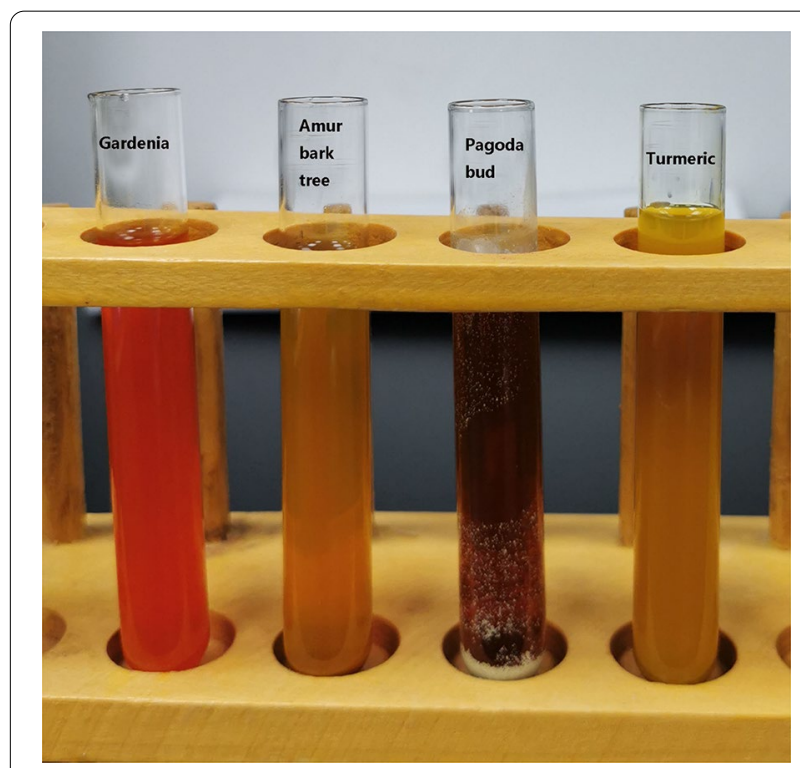

Fig. 2 Photographic images of prepared colorant dyes

\section{Color change measurements of paper}

The change in the color of the paper was determined using a solid reflection spectrophotometer (CM-700D from Minolta Co., Japan) according to the standard ISO 11475:2004 [18]. The conditions used in the experiment were the standard illuminant D65 and the $10^{\circ}$ observer. The CIEL"a*b* color space was used, and the color variations were evaluated using the parameter total color difference $\left(\Delta \mathrm{E}^{*}\right)$. The samples were always measured at five identical places. The average color difference was expressed as $\Delta E=\sqrt{(\Delta L *)^{2}+(\Delta a *)^{2}+(\Delta b *)^{2}}$.

\section{ATR-FTIR analyses}

Infrared spectra were obtained with a Thermo Nicolet iZ10 FTIR (Thermo Scientific Instrument) spectrophotometer combined with a Smart Orbit single reflection diamond attenuated total reflectance (ATR) accessory from 4000 to $650 \mathrm{~cm}^{-1}$ for 128 scans with $4 \mathrm{~cm}^{-1}$ spectral resolution. The FTIR microscope was equipped with an internal pressure sensor, a very precise and accurate motorized $\mathrm{X}-\mathrm{Y}$ stage, and an MCT detector and was cooled with liquid nitrogen.

\section{Thermal analysis}

Thermogravimetric (TG) analysis was carried out with a TGA 550 (Thermal Analysis Instrument). The samples were heated from room temperature to $900{ }^{\circ} \mathrm{C}$ at a rate of $10{ }^{\circ} \mathrm{C} / \mathrm{min}$ in the TGA instrument under ultrahigh-purified nitrogen at a flow rate of $25 \mathrm{~mL} / \mathrm{min}$.

\section{Mechanical property measurements}

All the paper samples were conditioned according to ISO 187-1990 [19] before mechanical measurements at a temperature of $23 \pm 1^{\circ} \mathrm{C}$ and an $\mathrm{RH}$ of $50 \% \pm 2 \%$ for $24 \mathrm{~h}$.

The mechanical properties were determined according to the TAPPI and ISO standards. Tensile strength test specimens were prepared by cutting samples $15 \mathrm{~mm}$ wide with sides within $0.1 \mathrm{~mm}$ and $250 \mathrm{~mm}$ long in the horizontal and vertical directions. Tensile strength tests on dyed and undyed paper sheets were performed on a computer-controlled TMI 84-56 tensile tester (horizontal) (Testing Machines, Inc., Holland) at room temperature using an extensometer gauge of $180 \mathrm{~mm} \times 15 \mathrm{~mm}$, load cells of $100 \mathrm{~N}$ and a test speed of $25 \mathrm{~mm} / \mathrm{min}$. All tests were carried out according to the TAPPI T-494 and ISO

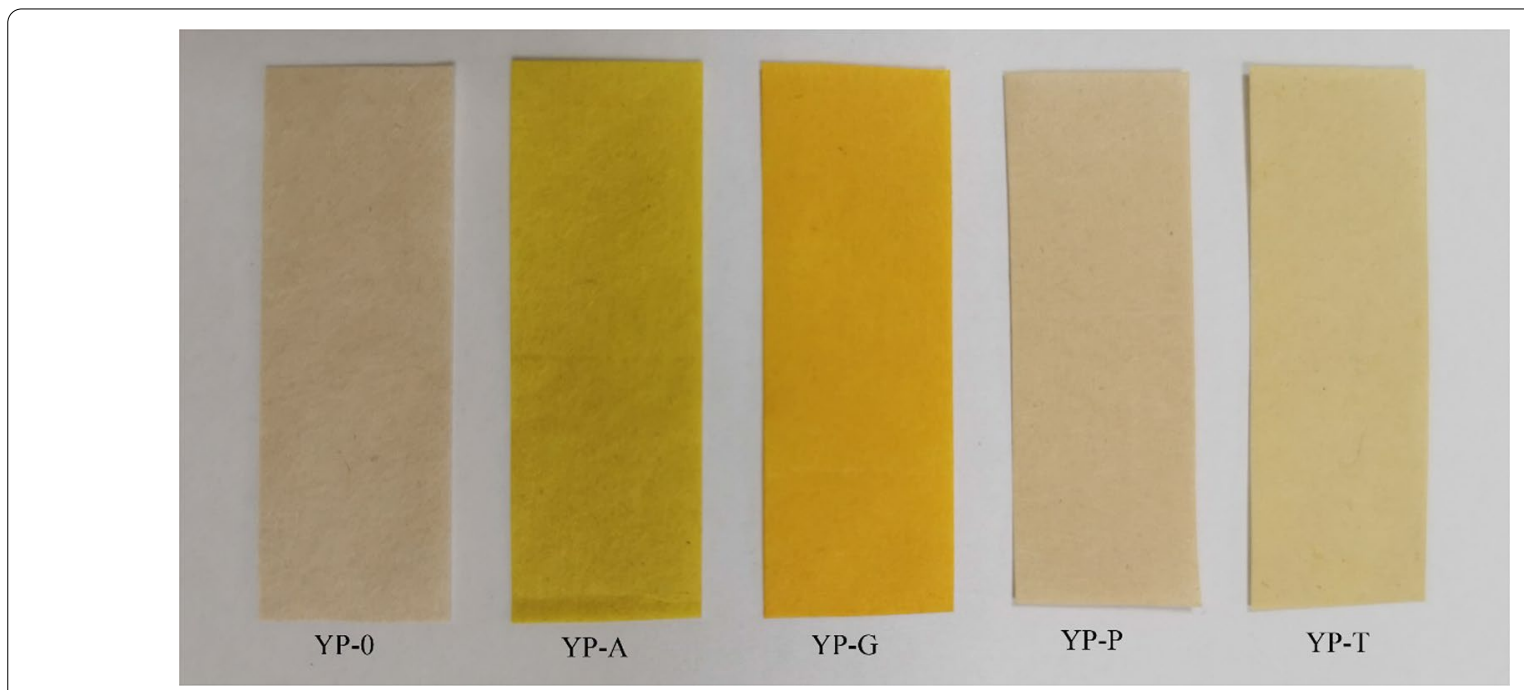

Fig. 3 Photographic images of dyed papers 
Table 1 The colour changes of paper samples after dyeing with different botanical sources

\begin{tabular}{|c|c|c|c|c|c|}
\hline $\begin{array}{l}\text { Sample } \\
\text { Color }\end{array}$ & YP-0 & YP-A & YP-P & YP-G & YP-T \\
\hline Color & & & & & \\
\hline L & 76.36 & 71.35 & 73.72 & 69.74 & 75.28 \\
\hline a & 3.66 & 1.22 & 3.18 & 15.6 & 3.18 \\
\hline b & 17.35 & 57.44 & 25.9 & 57.5 & 27.02 \\
\hline$\Delta \mathrm{E}$ & - & 40.48 & 8.97 & 42.28 & 9.74 \\
\hline
\end{tabular}

1924 standards $[20,21]$. The reported values were calculated as the averages of at least ten specimens.

The folding endurance experiments were performed on a TMI 31-23 folding endurance tester (Testing Machines, Inc., USA) according to TAPPI/ANSI T511 [22] and ISO5626:1993 [23] with standard $14 \mathrm{~cm}$ long by $15 \mathrm{~mm}$ wide paper samples. The applied force was $0.5 \mathrm{Kg}$ and double folds were 175 per minute. The reproted values were calculated as the averages of at least ten specimens.

\section{Microscope examination}

Scanning electron microscopy (SEM) images were recorded with a Philips FEI INSPECT F instrument operated at 5 or $10 \mathrm{kV}$ working voltage after specimen coating with a very thin gold layer deposited by sputtering under vacuum. The surface of the paper specimens was examined.

\section{Results and discussion}

Figures 1 and 2 show images of different dye plants and obtained liquid colorant dyes, respectively, under experimental conditions. In general, plant dyes caused highly visually perceptible color changes in the papers relative to their untreated counterparts [16]. The T dyes, G dyes, P dyes, and A dyes showed orange-red colors, yellow-brown colors, tea colors, and yellow-brown colors, respectively.

Colorimetric information was obtained by employing the International Commission on Illumination CIELAB color space, which mathematically simulates the perception of color by providing a standard process for measuring and quantifying color changes according to the standard test method (ISO11475:2004). The variables L*, $A^{*}$, and $B^{*}$ of the International Commission on Illumination (CIE) color space are used to designate lightnessdarkness, redness-greenness and yellowness-blueness, respectively. The variation in the colorimetric coordinate $\mathrm{L}^{*}, \mathrm{a}^{*}$ and $\mathrm{b}^{*}$ values is shown in Table 1 . All dyed paper samples showed a reduction in lightness after dyeing with plant dyes, but the effects on redness and yellowness were different. The papers treated with A colorants experienced a slight reduction in redness and a strong
Table 2 PH results and weight changes of dyed papers

\begin{tabular}{lccccc}
\hline Sample & YP-0 & YP-A & YP-P & YP-G & YP-T \\
\hline pH & 7.8 & 6.71 & 6.65 & 6.02 & 6.98 \\
Weight change (\%) & - & 11.6 & 21.8 & 13.5 & 11.9 \\
\hline
\end{tabular}

Table $3 \mathrm{PH}$ results of colorant dyes

\begin{tabular}{lllll}
\hline $\begin{array}{l}\text { Botanical } \\
\text { sources }\end{array}$ & Amur cork tree & Pagoda bud & Gardenia & Turmeric \\
\hline $\mathrm{pH}$ & 6.12 & 6.42 & 4.51 & 6.54 \\
\hline
\end{tabular}

increase in yellowness, which suggested that A had the greatest yellow effect on the paper samples. The color changes recorded for the $G$ paper samples revealed an increase in both redness and yellowness but less yellowness than samples treated with A dyes, which suggested that the $\mathrm{G}$ dyed paper samples showed a significant redyellow color. The paper samples treated with $\mathrm{P}$ and $\mathrm{T}$ dyes exhibited only a reduction in redness and a slight increase in yellowness, representing the smallest color change. The different color results demonstrated that the different dyes had different toning effects.

The $\mathrm{pH}$ results of the colorant dyes and paper samples are shown in Tables 2 and 3. According to Table 3, the undyed paper samples demonstrated weak alkalinity $(\mathrm{pH}=7.8)$, which might be ascribed to the presence of alkaline materials during the papermaking process. After treatment with different plant dyes, the paper samples had a slightly lower $\mathrm{pH}$ than the undyed paper. By comparing Tables 2 and 3, it was found that the decreased $\mathrm{pH}$ of different dyed papers was induced by adding plant dyes that reacted with weak alkaline paper. Additionally, the different $\mathrm{pH}$ results and color changes demonstrated that the main components of these plant dyes were different. These results corresponded with reports that most plant dyes could decrease the $\mathrm{pH}$ of paper [24]. In the experiments, the $\mathrm{G}$ dyes exhibited the lowest $\mathrm{pH}$. The main dye constituents of $\mathrm{G}$ include crocin and crocetin (shown in Fig. 4), both of which are yellow dyes with high tinctorial 


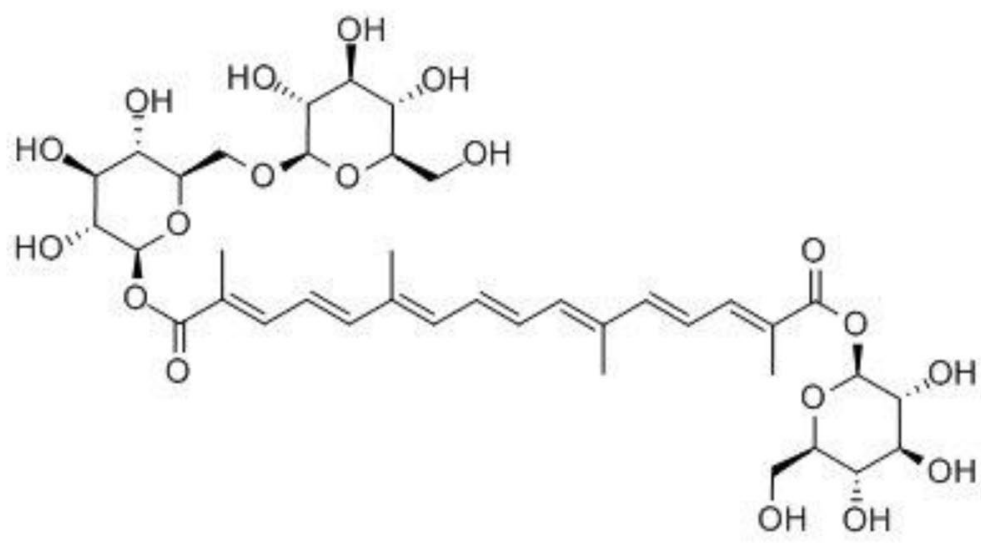

crocin<smiles>CC(/C=C/C=C(\C)C(=O)O)=C\C=C\C=C(C)\C=C\C=C(/C)C(=O)O</smiles>

crocetin

Fig. 4 The characteristic components of gardenia

strength and produce a golden-yellow hue on almost all materials. Crocin, with the molecular formula $\mathrm{C}_{44} \mathrm{H}_{24} \mathrm{O}_{4}$ and a molecular weight of 997.21, contains natural glucoses on both sides of the molecule. Crocetin, with a molecular formula of $\mathrm{C}_{20} \mathrm{H}_{24} \mathrm{O}_{4}$ and molecular weight of 328.4, contains carboxyl groups attached to both sides; these groups cause the G solution to have the lowest $\mathrm{pH}$. It was reported that the carotenoid pigments extracted from $G$ could be larger than those extracted from saffron [25]. However, $\mathrm{G}$ is quite unstable under light and alkaline conditions. For A, its main colored compound is berberine (shown in Fig. 5), with a strong yellow color and the molecular formula $\mathrm{C}_{20} \mathrm{H}_{18} \mathrm{NO}_{4}$, which can be positively charged with protons to form a cationic alkaloid. The weak acidity might be due to the presence of obacunonic acid, ester, ketone and polysaccharide in solution. The main colored compound in $\mathrm{T}$ is curcumin (shown in Fig. 6). The phenol group in curcumin makes the $\mathrm{T}$ solution weakly acidic. Curcumin, which exhibits a yellow color and has a diferuloyl methane structure and a molecular weight of 368.4, was isolated in the nineteenth century [26]. Its colorant consists of a mixture of compounds known as curcuminoids. The main colorant in the $\mathrm{P}$ was rutin (shown in Fig. 7). Rutin, with the molecular formula $\mathrm{C}_{27} \mathrm{H}_{30} \mathrm{O}_{16}$ and a molecular weight of 610.5 , is a yellow crystalline flavonol glycoside that was isolated and identified by Stein in 1853 [27]. The four phenolic hydroxyl groups in rutin might be the reason why the solution is weakly acidic. Due to the different main

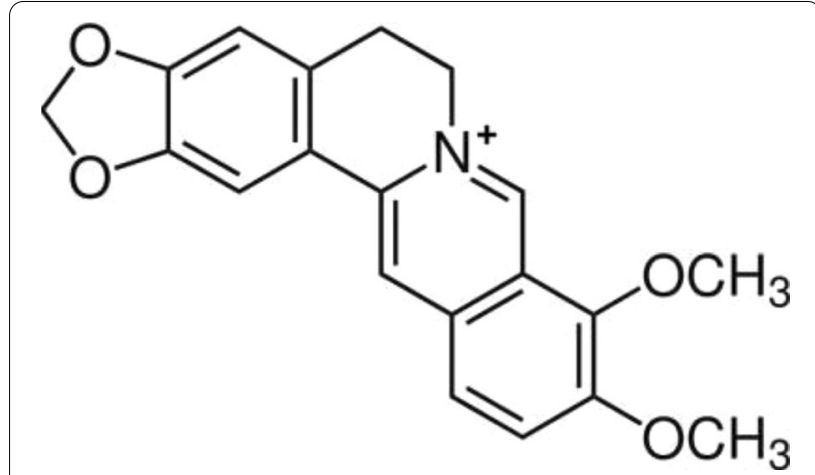

Fig. 5 Berberine, the characteristic components of Amur cork tree<smiles>COc1cc(/C=C/C(=O)/C=C(O)/C=C/c2ccc(O)c(OC)c2)ccc1O</smiles>

Fig. 6 Curcumin, the characteristic component of turmeric

components of the dyes, the dyed paper samples yielded different $\mathrm{pH}$ results, although all of the dyed papers had a slightly lower $\mathrm{pH}$ than the undyed papers. The presence of carotenoid pigments in $\mathrm{G}$ affected the $\mathrm{pH}$ of the dyed paper. To determine whether the $\mathrm{pH}$ change accelerates 


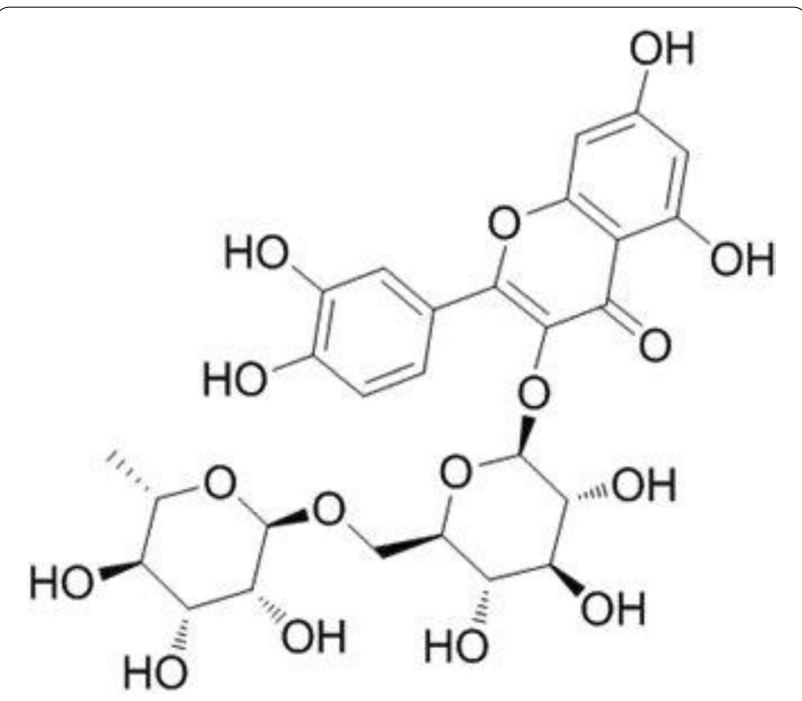

Fig. 7 Rutin, the characteristic components of pagoda bud

the instability of the paper during aging, we are conducting aging tests under thermal and UV-light artificial accelerating conditions. We will share our results in other reports in the near future.

Table 2 shows that the weight change of the paper samples was different after dyeing. A higher weight increase could indicate that larger materials were absorbed on the paper surfaces. The P-treated paper specimens exhibited the highest weight change. According to the main components of different plant dyes, all of the rutin, curcumin, crocin and crocetin molecules included hydroxyl structures, which can form hydrogen bonds with paper cellulose and semicellulose and may be contribute to the weight increase. Other materials, such as solvent water, could be absorbed by these colorant dyes. The molecular weight and the number of hydroxyl structures in the dyes affected the weight change of the paper. For these different dyes, berberine has no hydroxyl structure; however, the presence of nitrogen means it could be positively charged with the ability to form a salt. Rutin has the largest number of hydroxyl groups and highest molecular weight of the colorant materials, which might be why the P-dyed paper exhibited the highest weight increase. These absorbed materials might act as barriers to defy attack from the paper's environment.

To further identify the effects of different colorant components on paper, TG analysis was used to obtain the mass loss as a function of temperature for different samples. Figure 8 shows that the weight loss for all samples was between 280 and $400{ }^{\circ} \mathrm{C}$, which corresponds with paper fiber decomposition, resulting in volatiles and low molecular weight materials such as $\mathrm{CO}_{2}, \mathrm{CO}$, ketones and aldehydes. For the nondyed paper, the removal of free water began ca. $55^{\circ} \mathrm{C}$. The highest decomposition temperature was ca. $356{ }^{\circ} \mathrm{C}$. After that, the weight loss of the samples was small, and a carbonization process and rearrangement of aromatic rings began. Figure 8 shows that the A dyed paper specimens had higher decomposition temperatures than the undyed paper. However, the G-, T- and P-dyed papers displayed lower onset and end decomposition temperatures. The different TG results demonstrated that there were chemical bonds between the colorant and paper fibers. The chemical bonds could affect the thermal stability of the paper samples. According to the characteristic components of different dyes, the decomposition of rutin, crocin and curcumin could produce weak acid materials due to the existence of carboxyl and ketone groups, which could accelerate the decomposition of paper fibers under high temperature conditions. The experiments demonstrated that the dyed papers had lower thermal stability. The G-dyed paper had a higher weight increase and decomposition temperature than the P-and T-dyed papers. This result meant that the hydrogen bond between the paper and colorant dyes could affect the decomposition temperature. The A dyed paper had a higher decomposition temperature than the nondyed paper, which could be ascribed to the fact that berberine more strongly interacted with the paper fibers. The FTIR results (Fig. 9) showed a chemical bond ca. $1337 \mathrm{~cm}^{-1}$, which was ascribed to the aromatic amine of the A dyed paper, while the other yellow dyed papers had no such characteristic bond. The aromatic amine of A could form a chemical bond with the hydroxyl groups of the paper fibers through nitrogen. The TG results further indicated that the positively charged nitrogen and hydroxyl groups exhibited a stronger interaction than the hydrogen bonds of the oxygen and hydroxyl groups.

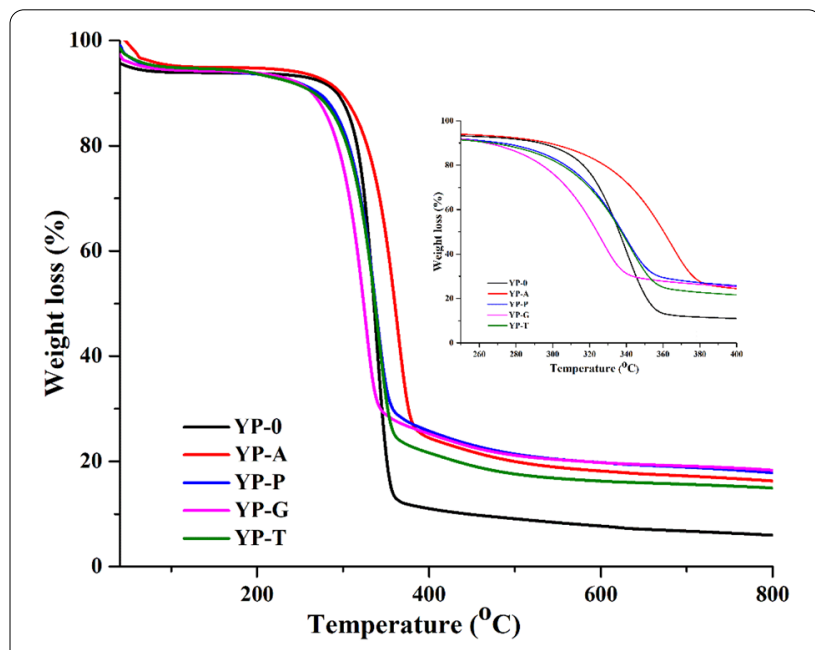

Fig. 8 TG results of dyed papers 
To identify how the toning materials affected the mechanical properties of paper, tensile strength and folding endurance experiments were conducted. The mechanical strength of handmade paper is determined by the intrinsic strength of the fibers and the bonding strength between fibers. Additionally, the tensile strength of handmade paper is different in different directions. The tensile strength of traditional handmade paper usually depends on the orientation along the longitudinal direction (LD) and transverse direction (TD). The average values of the tensile strength and breaking length are shown in Figs. 10 and 11. The undyed paper had tensile strengths of ca. $21.8 \mathrm{~N}$ along the transverse direction and $19.6 \mathrm{~N}$ along the longitudinal direction. Slightly better tensile strengths and folding endurance were observed for the P-, T- and G-dyed papers. However, the A-treated paper specimens led to a distinctive improvement in the tensile strength and breaking length. These results could be explained by the different characteristic components of these colorant dyes, which affected the intrinsic resistance of the paper fibers within the experimental accuracy. The tensile strength is related to the binding force between fibers. The increases in the tensile strength and folding endurance were attributed to the formation of more electrostatic interactions due to the chemical reaction between the colorants and paper fibers. Furthermore, the A dye contained sugar materials that covered the fiber surface and led to an increase in the mechanical strength. To explain the mechanical properties, the surface paper specimens were further observed by SEM.

According to our Herzberg dye testing [28, 29], the main plants in the handmade paper specimens were

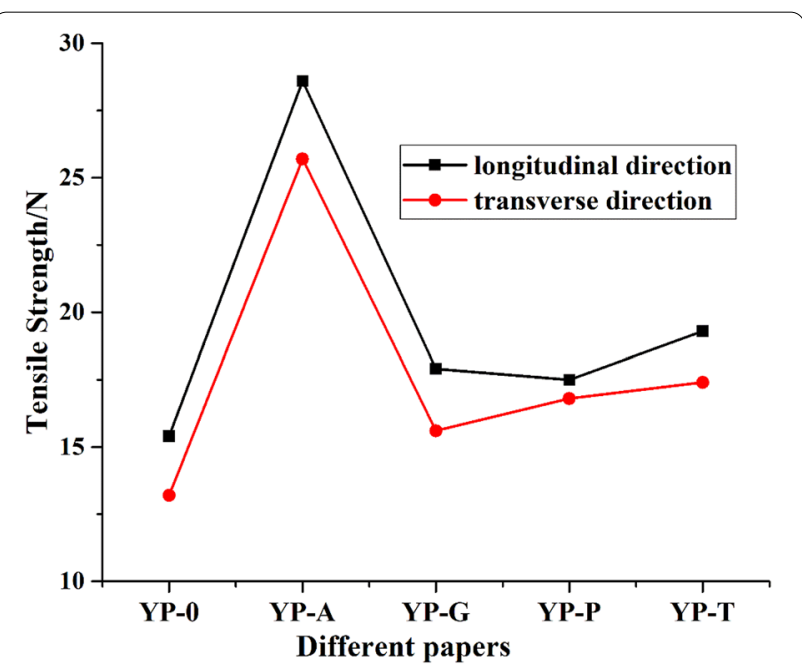

Fig. 10 Tensile strength values of dyed papers

Sinocalamus bamboo (Sinocalamus affinis (Rendle) McClure) and mulberry bark (Morus alba L.). SEM observations (in Fig. 12) indicated that the main plant included round tubular mulberry bark; the surface of the sample was uneven, and there were a few holes in the longitudinal direction and transverse stripes in the horizontal direction [30]. Joints, ravines and grooves were seen in the bamboo fibers [31]. After dyeing, the fibers were deposited by toning particle materials, some of which filled into the cracks, holes and ravines of the fibers, leading to a reduction in the porosity and pore size distribution. The filled colorant dyes could form chemical bonds with fibers by hydrogen bonds. This might be the reason for the improved mechanical

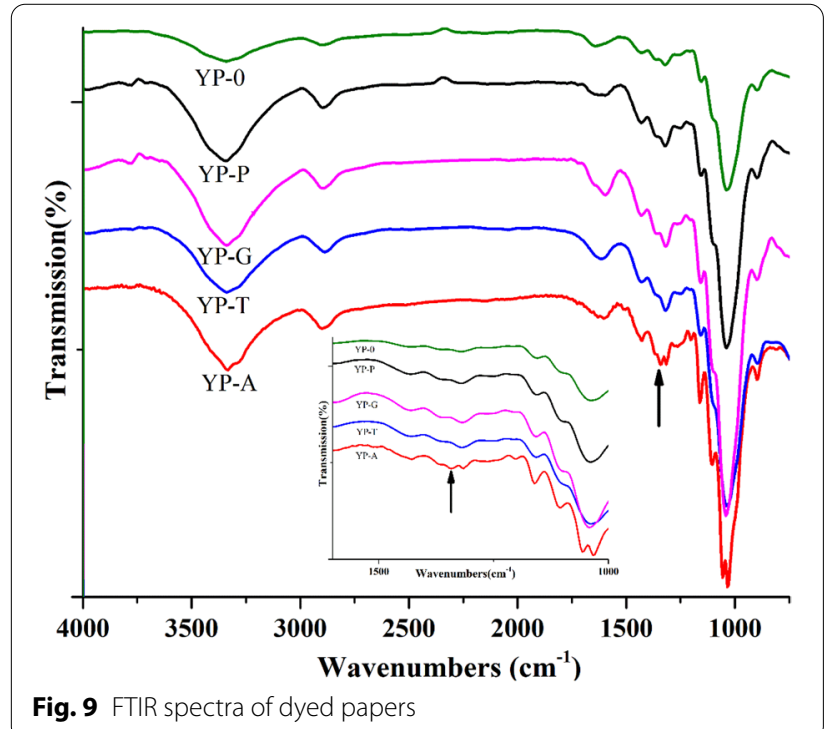

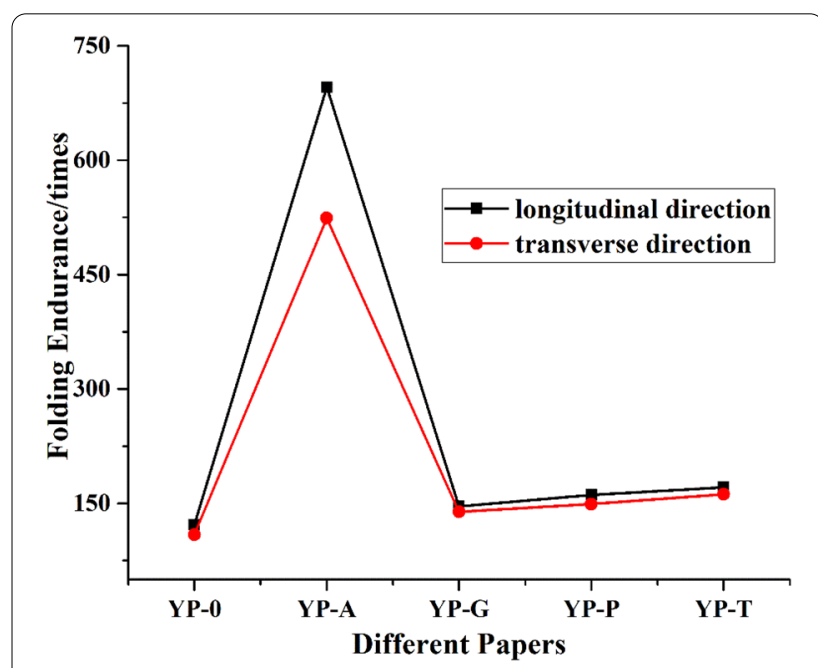

Fig. 11 Folding endurance values of dyed papers 

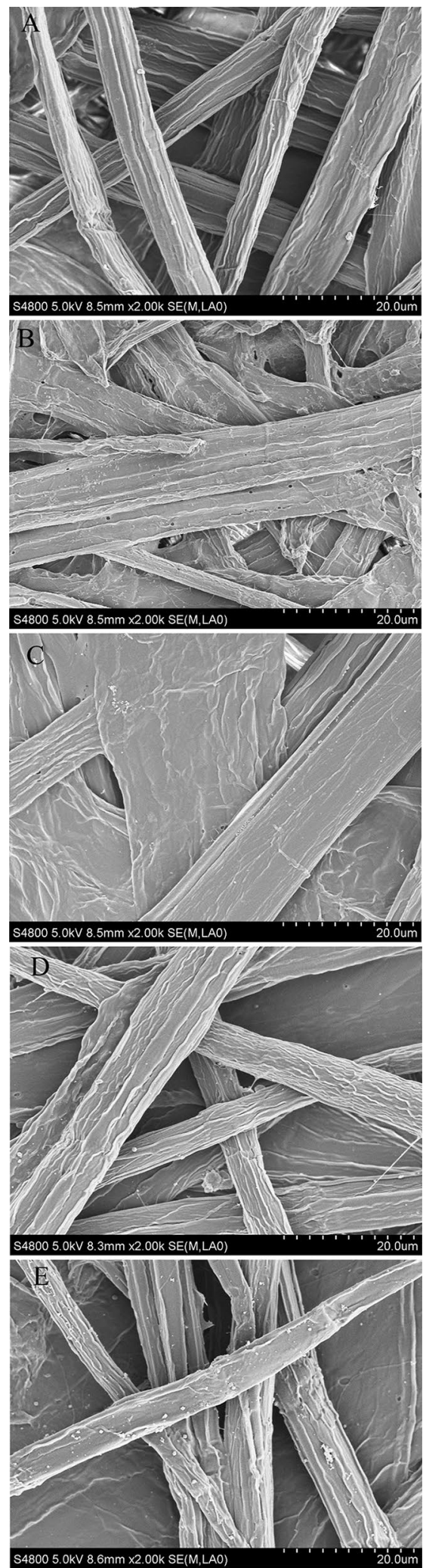

Fig. 12 SEM images of different papers. A undyed paper, B Amur cork tree dyed paper, $\mathbf{C}$ pagoda bud dyed paper, $\mathbf{D}$ gardenia dyed paper, E. turmeric dyed paper properties of all the dyed papers. The best mechanical properties found, induced by $\mathrm{A}$, were ascribed to the higher interfacial interaction due to the network and viscous substance coating on the paper surface and connecting the paper fibers. The mechanical test results confirmed that the electrovalent chemical bonds of the nitrogen and hydroxyl groups between the fibers and A were stronger than the interactions of the hydroxyl bonds induced only by the oxygen and hydroxyl groups. We will discuss how A affects the properties of the paper further in future work.

\section{Conclusions}

This experiment confirmed that handmade Daqian paper dyed with traditional botanical dye sources, such as Amur cork tree, turmeric, pagoda bud and gardenia, could have different properties. The different botanical sources had different effects on the properties, including the color, thermal stability and mechanical properties, due to their main characteristic components. The improved tensile strengths and folding endurances of these toning materials after dyeing are beneficial for paper. The chemical interaction between the Amur cork tree dyes and paper fibers had a stronger effect on the mechanical and thermal stability than those of the gardenia-, turmeric- and pagoda bud-treated paper due to the stronger hydroxyl-nitrogen bond and hydroxyl groups and viscous substances. This stability may be one of the reasons why most of the ancient books that currently still exist were dyed with yellow Amur cork tree dyes. All of these chosen yellow plant dyes slightly decreased the $\mathrm{pH}$ of handmade paper. We should be cautious when choosing how to conserve paper artifacts because some of them have a low $\mathrm{pH}$, which might affect the conservation of the paper artifacts.

\section{Abbreviations \\ TG: Thermogravimetric; LD: Longitudinal direction; TD: Transverse direction; ATR-FTIR: Attenuated total reflection flourier transformed infrared spectros- copy; SEM: Scanning electron microscopy; ClE: International Commission on Illumination; YP-0: The undyed paper samples; YP-A, YP-P, YP-G, YP-T, the Amur cork tree (A), pagoda bud $(P)$, gardenia $(G)$ and turmeric $(T)$ dyed paper samples, respectively.}

\section{Acknowledgements}

The authors gratefully acknowledge the financial support from the National key research and development project (Grant No.: 2019YFC1520404), the Joint Funds of the National Natural Science Foundation of China (Grant No.: U19A2045) and Science and Technology Support Programme of Sichuan Province (Grant No.: 2019YFS0494). We thanks Lingzhu Yu for her help with SEM measurements and Ren Wang for her assistant with mechanical tests.

\section{Authors' contributions}

Data were collected by YBL, XJZ. YBL and XJZ prepared and revised the manuscript. All authors read and approved the final manuscript. 


\section{Funding}

The research was supported by the National key research and development project (Grant No:: 2019YFC1520404), the Joint Funds of the National Natural Science Foundation of China (Grant No.: U19A2045) and Science and Technology Support Programme of Sichuan Province (Grant No.: 2019YFS0494).

\section{Availability of data and materials}

The datasets used and/or analyzed during the current study are available from the corresponding author on reasonable request.

\section{Declarations}

\section{Competing interests}

Not applicable for that statement.

\section{Author details}

'School of History and Culture, National Center for Experimental Archaeology Education, Sichuan University, Chengdu 610064, China. ${ }^{2}$ Chongqing Hongyan Revolution Museum, Chongqing 400043, China.

Received: 27 January 2021 Accepted: 7 July 2021

Published online: 19 July 2021

\section{References}

1. Gibbs PJ, Seddon KR, Brovenko NM, Petrosyan YA, Barnard M. Analysis of ancient dyed chinese papers by high-performance liquid chromatography. Anal Chem. 1997;69(10):1965-9.

2. Richardin P, Cuisance F, Buisson N, Asensi-Amoros V, Lavier C. AMS radiocarbon dating and scientific examination of high historical value manuscripts: application to two Chinese manuscripts from Dunhuang. J Cult Herit. 2010;11(4):398-403.

3. Tsien TH. Paper and Printing. Science and Civilization in China. Vol. 5, part 1: Chemistry and Chemical Technology. Cambridge: Cambridge University Press. 1985. pp 74-76.

4. Su S, Shang ZJ. Illustrated Classic of the Materia Medica (Bencao Tujing). Hefei: Anhui Scientific \& Technology Publishing House. 1994: 372 (in Chinese)

5. Shu YL. Ancient gardenia and its cultivation and utilization. Agric Hist China. 1992;12(3):78-84 (in Chinese).

6. Li SZ. Compendium of Materia Medica, rev. and puncturated (Bencao Gangmu: Jiaodianben). Beijing: People's Medical Publishing House. 1975. pp 968 (in Chinese).

7. Zhao KH, Zhou JH. A history of dyeing chemistry in ancient China (Zhongguo Gudai Ranse Huasueshi). In: History of Chinese science and technology, chemistry volume (Zhongguo Kexue Jishushi, Huaxuejuan). Beijing: Beijing Science Press; 1998. p. 640-1 (in Chinese).

8. Han J. The historical and chemical investigation of dyes in high status chinese costume and textiles of the ming and qing dynasties. (1368-1911) PhD Thesis, University of Glasgow, 2016: 86-158.

9. Gibbs PJ, Seddon KR. Berberine and huangbo: ancient colorants and dyes. London: British Library; 1998.

10. Zhang X, Mouri R, Mikage R, Laursen R. Preliminary studies toward identification of sources of protoberberine alkaloids used as yellow dyes in asian objects of historical interest. Stud Conserv. 2010;55(3):177-85.
11. Zhang X, Corrigan K, MacLaren B, Leveque M, Laursen R. Characterization of yellow dyes in nineteenth-century chinese textiles. Stud Conserv. 2007:52(3):211-20.

12. Liu J, Ji LF, Chen L, Pei KM, Zhao P, Zhou Y, Zhao F. Identification of yellow dyes in two wall coverings from the Palace Museum: evidence for reconstitution of artifacts. Dyes Pigm. 2018;153:137-43.

13. Bell SEJ, Bourguignon ESO, Dennis AC, et al. Identification of dyes on ancient Chinese paper samples using the subtracted shifted Raman. Anal Chem. 2000;72(1):234-9.

14. Song YX, Pan JX. Exploitation of products from the nature by combination of artificial skills and natural power (Tiangong Kaiwu). Shanghai: Shanghai Chinese Classics Publishing House; 2007. p. 118-26.

15. Cardon D. Natural dyes: sources, tradition, technology and science. London: Archetype Publication Ltd.; 2007. p. 322-34.

16. Soleymani S, Ireland T, Mcnevin D. Effects of plant dyes, watercolors and acrylic paints on the colorfastness of japanese tissue papers. J Am Inst Conserv. 2016;55(1):56-70.

17. ISO 6588-1: 2012, Paper, board and pulps-Determination of $\mathrm{pH}$ of aqueous extracts- part 1: Cold extraction. 2012.

18. ISO 11475: 2004, Paper and board-Determination of CIE whiteness, D65/10 (outdoor daylight). 2004.

19. ISO 187: 1990, Paper board and pulps-Standard atmosphere for conditioning and testing and procedure for monitoring the atmosphere and conditions of samples. 1990.

20. TAPPI T494 om-13, Tensile properties of paper and paperboard (using constant rate of elongation apparatus). 20013.

21. ISO 1924-2: 2008, Paper and board-Determination of tensile propertiesPart 2: Constant rate of elongation method ( $20 \mathrm{~mm} / \mathrm{min}) .2008$.

22. TAPPI T511 om-13, Folding endurance of paper (MIT tester). 2013.

23. ISO 5626: 1993, Paper-Determination of folding endurance. 1993.

24. Soleymani S. The effects of plant dyes, watercolours and acrylic paints on the physical, chemical and biological stability of Japanese tissue paper used in paper conservation. PhD Thesis, University of Canberra, 2015.

25. Cardon D. Natural dyes: Sources, Tradition, Technology and Science. London: Archetype Publication Ltd.; 2007. p. 308.

26. Govindarajan VS, StahI WH. Turmeric-chemistry, technology, and quality. CRC Crit Rev Food Sci Nutr. 1980;12(3):199-301.

27. Cardon D. Natural dyes: sources, tradition, technology and science. London: Archetype publications Ltd.; 2007. p. 211.

28. TAPPI 401OS-74, Fiber analysis of paper and paperboard. 1975.

29. ISO 9184-3, Paper, board and pulps-Fiber furnish analysis-Part 3: Herzberg test. 1990.

30. Chen GX, Chen HW. Structure and performances of mulberry bark. J Nant Text Vocat Technol Coll. 2009;9(1):10-3 (in Chinese)

31. Wang LM, Sheng Y, Zhang HF, et al. Characteristic bamboo fibers and study its products. J Text Dye Finish. 2011;33(8):17-21 (in Chinese)

\section{Publisher's Note}

Springer Nature remains neutral with regard to jurisdictional claims in published maps and institutional affiliations.

\section{Submit your manuscript to a SpringerOpen ${ }^{\circ}$ journal and benefit from:}

- Convenient online submission

- Rigorous peer review

- Open access: articles freely available online

- High visibility within the field

- Retaining the copyright to your article

Submit your next manuscript at springeropen.com 